\title{
Assessment of Nutritional Status of School Children in Public and Private Sector Schools by Anthropometry
}

\author{
Qamar Mehboob ${ }^{1}$, Sana Arif ${ }^{2}$, Waqar Arif ${ }^{3}$
}

1 Associate Professor, Department of Physiology, Faisalabad Medical University, Faisalabad Pakistan

1 Completion of results, Statistical analysis

2 House Officer, Allied Hospital, Faisalabad Medical University, Faisalabad, Pakistan

2 Data Collection

Post Graduate Resident Plastic Surgery Department, Allied Burn E Reconstructive Surgery Center Faisalabad 3 Medical University, Faisalabad, Pakistan

Manuscript designing, Tabulation of results

CORRESPONDING AUTHOR

Dr. Qamar Mehboob

Associate Professor, Department of Physiology,

Faisalabad Medical University, Faisalabad Pakistan

Email: qamarmehboob89@yahoo.com

Submitted for Publication: 26-10-2020 Accepted for Publication 03-03-2021

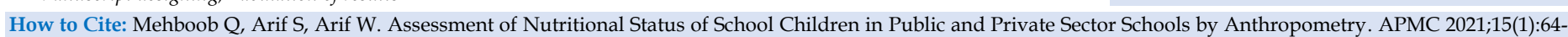
8. DOI: $10.29054 / A P M C / 2021.1070$

\section{ABSTRACT}

Background: Nutrition is the real determinant of human health. The development of children into healthy adults is dependent on their growth, in a healthy environment and having balanced nutrition. Objective: (1) To determine the association of nutritional status of children with their age, sex and socioeconomic status. (2) To compare the nutritional status of government school children and private school children. Study Design: Comparative cross-sectional. Settings: Study was conducted in two schools of Faisalabad, Pakistan. Government Girls high school, Punjab Medical College (PMC), Colony Faisalabad and The Smart School, Faisalabad. Duration: Eight months from Jan 01, 2020 - Aug 30, 2020. Methodology: The study was conducted on 200 children, including males \& females, to compare weights and heights among government (government) and private (private) schools. Age groups ranging from 9 above to 14 years were being studied. The data was collected by taking anthropometric measures, height and weight, of the students. To assess the nutritional status, the anthropometric measurement of WHO 2007 reference was used as Weight for Age Z-score (WAZ), Height for Age Z-score (HAZ) and Body Mass Index (BMI) for Age Z-score (BAZ). Descriptive statistics and Pearson's correlation test were used for statistical analysis. Data was analyzed statistically by using SPSS version 20. Results: The weight of private school children $(39.3400 \pm 2.39199)$ was normal as they have adequate diet as compared to government school children $(38.7500 \pm 1.43812)$ while $2 \%$ children were over weighted. Height of private school children (147.7600 \pm 5.04949) was more as compared to government school children (146.8100 \pm 4.34310$)$. Statistically Pearson Correlation between weight of private and government school's children was highly significant, $\mathrm{p}=0.000, \mathrm{df}=1, \mathrm{CI}=95 \%$. Demographic information with height and weight of the children were taken. Z-score was calculated and graphs were plotted. A value within \pm 2 SD in these graphs was considered as normal. Conclusion: Socio-economic status affects the availability and quality of food. For under-weight Children, unhygienic and low-quality food/stuffs are the major contributing factors.

\section{Keywords: Nutrition, School, Anthropometery.}

\section{INTRODUCTION}

The growth of a child is being considered as an important indicator to assess health trends in a population and to devise strategies accordingly. ${ }^{1}$ The study of growth in children should be viewed at a larger scale as this developing process starts from intra uterine developmental stage and slowly reaches to infancy, early childhood up to adolescence. An individual's future health status especially of the somatic growth occurs mainly during childhood and adolescent period. Furthermore, it is strongly linked to adult weight and cardiovascular health status. ${ }^{2}$

To determine normative reference values in a population, monitoring of children's growth has now become an important tool. It assists healthcare providers to identify any growth abnormality earlier. By taking early preventive measures one can avoid its further abnormalities.

Anthropometry is a widely used portable, simple and easy to apply, inexpensive, technique which involves several body measurements. For evaluation of nutrition status of children and adults the best anthropometry parameters are height, weight and Body Mass Index (BMI). ${ }^{3}$ This technique is universally acceptable as it is not only simple, non-invasive and economical but also the most accurate. ${ }^{4}$

Malnutrition has been identified as a factor in growth and learning. According to World Health Organization (WHO) data, under 5 years old, 155 million children suffer from chronic malnutrition leading to neuro developmental delay and 2 billion people suffer from some degree of malnourishment. For the study population scoring below the expected performance, 
considering their developmental age, neuropsychological tests such as Beery-Buktenica Visual-Motor Integration test (VMI), Battery of Differential and General Abilities (BADYG) and the Human Figure Drawing test (HFD) can be performed. ${ }^{5}$ These tests evaluate language and visuomotor skills, which are prerequisites for reading and writing, acquired in formal elementary school education. Cultural variations do not affect VMI and HFD tests. ${ }^{6}$ While Development of visuomotor skills stars in childhood and depend on environmental stimuli. The BADYG test, evaluating verbal skills, is affected by variations in culture, context, and upbringing.

United Nation Education, scientific and Cultural Organization have announced their goal: "Quality Education and Lifelong Learning for all by 2030". Primary education plays a very important role to achieve this goal. Under-nourished children have delayed cognitive development and underachievement of their study performance. It is reported that worldwide, by 2025 , over 450 million children will be affected by stunting which is the impact of chronic under nutrition. ${ }^{8}$ In 2017, Hayashi $\mathrm{C}$ et al reported that Africa shared $27 \%$ wasted, $38 \%$ stunted and $24 \%$ overweight children in under-five children. In West Africa region, reported stunting rate was $19.2 \% .^{9}$

The nutritional status of school children impacts their health, growth and development, cognition and subsequently their educational status. To improve the health and nutrition of school going children, schools are the best places to deliver an integrated package of interventions such as micro nutrition supplements and other nutritious meals, health promotion, infection control and life skills education.

Through a lot of research work, various researches proved the importance of well nourishment for its positive effect over learning and cognitive performance, intelligence, maintaining education and academic achievements, thereby preserving the world for the adverse effect of malnutrition. It can not only cause acute and chronic illnesses but after suffering for several years, can lead to death also. Recent reported prevalence showed that $52 \%$ pregnant women and $72 \%$ infants are having anemia and $44 \%$ children under five years of age are underweight. ${ }^{10}$ Due to the deficiency of essential nutrients and poor socio-economic living conditions, people living in urban slum areas are at increased risk of morbidity and mortality. ${ }^{11}$ Moreover, for earning, many people shifted to the cities and town. In many developing countries, a large proportion of this migrating population ends up residing in slums in inhuman conditions. As a result, urban poverty and hunger are increasing. Lack of basic necessities, like proper housing, safe drinking water, proper drainage and excreta disposal give more harm to this population exposing them to different types of infections also.
A balance diet is essential to fulfill the need of basic nutrients and it is a part of life for those who are facing its deficiency problems. To prevent malnutrition, we can increase the diversity of the available food also ${ }^{12}$. Insufficient daily intake of different food stuff badly affects a child's health and obstructs his learning process. Our country, Pakistan, stands among those countries which are facing the dual burden of thinness/stunting on one hand and/or overweight/obesity on other hand. Recently, from a survey of 57 low- and middle-income countries of school aged children, a dual burden of under nutrition and over nutrition has been reported in Pakistan. ${ }^{12}$ The largest province of Pakistan is Punjab, area of which is $205,345 \mathrm{Km}^{2}$ and the population is over 110 million. Regarding Punjabi schoolgirls, the incidence of stunting and thinness is very high as compared to overweight / obesity..$^{13}$ So, we planned to conduct the present research work to assess the general health and nutritional status of school going children at Faisalabad.

Objectives:

1. To determine the association of nutritional status of children with their age, sex and socioeconomic status.

2. To compare the nutritional status of government school children and private school children.

\section{METHODOLOGY}

Study Design: Comparative cross-sectional study.

Settings: Study was conducted in two schools of Faisalabad Pakistan. Government Girls High School, PMC Colony, Faisalabad \& The Smart School Faisalabad. Duration: Eight months from Jan 01, 2020 - Aug 30, 2020. Sample Technique: Stratified sampling technique.

Sample Size: It was calculated according to following formula:

$$
n=\frac{z_{1-\alpha / 2}^{2} * p^{*}(1-p)}{d^{2}}
$$

where $n$ is the calculated sample size, Z1-a/2 is Z score at $1-a / 2$ confidence level, ' $p$ ' is the estimated proportion and ' $d$ ' is largest difference of the estimated proportion that could be accepted in the research. A total of 200 children, 100 from each school were selected for the collection of data.

Inclusion Criteria: Only the school going children belonging to a specific government or private school of age (in years) groups 9-14 were selected.

Exclusion Criteria: Children below 9 and above 14 years. Suffering from any specific disease.

Data Collection Procedure: The data was collected by taking anthropometric measures, height and weight, of the students. To assess the nutritional status, the anthropometric measurement of WHO 2007 reference was used as Weight for Age Z-score (WAZ), Height for Age Z-score (HAZ) and Body Mass Index (BMI) for Age Z-score (BAZ). The weight of the participants was measured in Kilograms without shoes and with light 
clothing using a digital scale (Tanita HA-623, LOT \# 820831, China). The measurement of maximum vertical size of the body that is "The Standing Height" was measured with Stadiometer (Charder HM210D, USA), consisted of a vertical stand and an adjustable headpiece. Correct body posture was attained, while recording the standing height. Descriptive statistics and Pearson's correlation test were used for statistical analysis. Data was analyzed statistically by using SPSS version 20 .

\section{RESULTS}

In terms of normal BMI $=(\mathrm{kg} / \mathrm{m} 2)$, both the schools had the high proportion of students. They both have almost 72 students with normal BMI. However, it was observed that the students of private school have slightly higher percentage $(40 \%)$ of students with normal BMI as opposed to the students of government school with $32 \%$ of Normal BMI. There were more underweight students in government school with $64 \%$ as compared to students of private school with $60 \% \mathrm{BMI}$, about $4 \%$ of students "at the risk of becoming overweight". The mean BMI for private and government school children was $18.0199 \pm$ 1.18686 and $17.1091 \pm 1.67246$ respectively with age from 9 -14 years and BMI 15.81 to 21.84 .

The comparison of weights of government and private school children on the basis of BMI value indicating that 40 students from private school having normal weight while 32 students from government school having normal weight. 60 students are underweighting from private school and 64 students are underweight from government school. 4 students having over weight from government school (Graph 1).

Graph 1: Comparison of weight among government and private school children

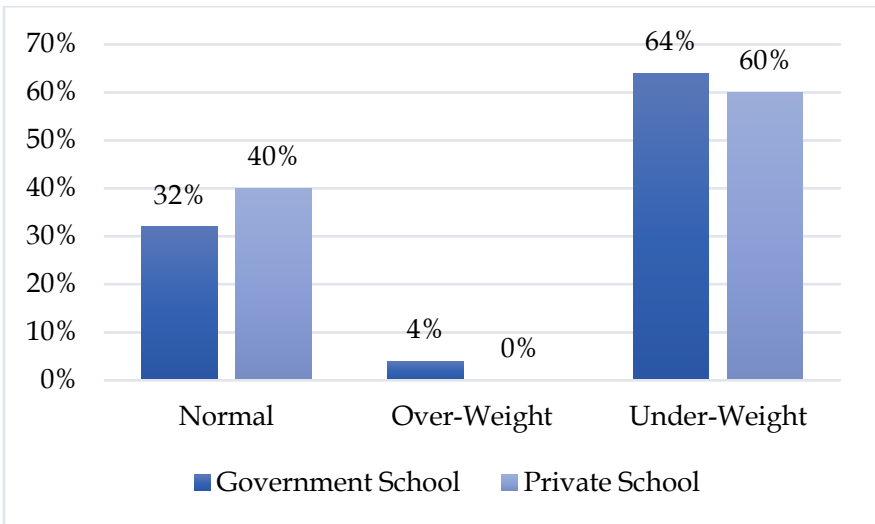

In combined Bar diagram shows different weights of students of government and private schools with respect to their age groups i.e., $30 \%$ students are of normal weight in age group 9-11 year and $40 \%$ students are of normal weight in age group from 12-14 year. (Table 1) (Graph 2).
Table 1: Weight of students of government and private schools with respect to their age groups

\begin{tabular}{|c|c|c|}
\hline $\begin{array}{c}\text { Age group } \\
\text { (Years) }\end{array}$ & $\begin{array}{c}\text { Private School } \\
\text { (Weight in kg) }\end{array}$ & $\begin{array}{c}\text { Government School } \\
\text { (Weight in kg) }\end{array}$ \\
\hline $9-11$ & $36.1399 \pm 6.82324$ & $37.1167 \pm 1.2278$ \\
\hline $12-14$ & $45.2139 \pm 2.2771$ & $41.2119 \pm 5.1712$ \\
\hline
\end{tabular}

Graph 2: Weight of students of government and private schools with respect to their age groups

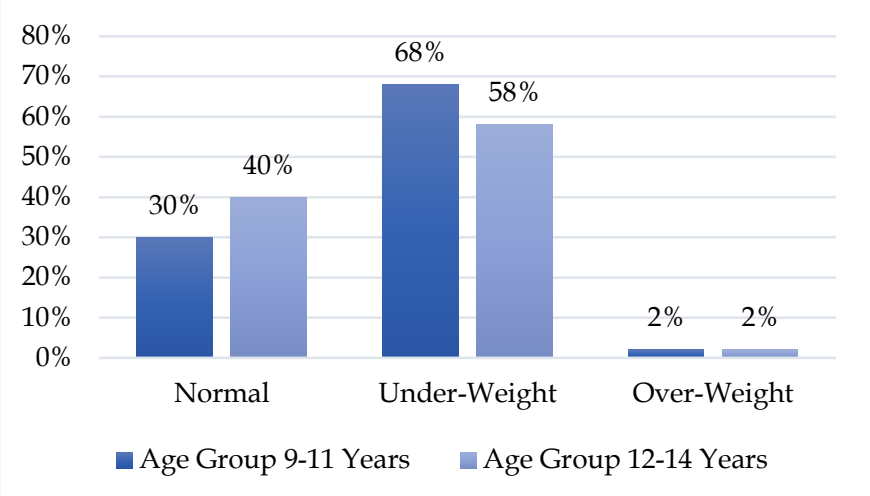

$68-70 \%$ students are of underweight having age group 911 years and $58-60 \%$ students are of underweight in age group 12-14 years. Lastly few (2) \%age of students with overweight are also seen in age group $9-11 \%$ years and 12-14 years.

Mean Weight (in kg) for government school children was $38.7500 \pm 1.43812$ \& for private school children was $39.3400 \pm 2.39199$.

Correlation of weight, between government and private school children $(n=100)$

\begin{tabular}{|c|c|c|c|}
\hline \multicolumn{2}{|c|}{ Correlations } & $\begin{array}{c}\text { Weight } \\
\text { (Government) }\end{array}$ & $\begin{array}{c}\text { Weight } \\
\text { (Private) }\end{array}$ \\
\hline \multirow{3}{*}{$\begin{array}{c}\text { Weight } \\
\text { (Government) }\end{array}$} & Pearson Correlation & 1 & $.662^{* *}$ \\
\hline & Sig. (2-tailed) & & .000 \\
\hline & $\mathrm{N}$ & 100 & 100 \\
\hline \multirow{3}{*}{$\begin{array}{l}\text { Weight } \\
\text { (Private) }\end{array}$} & $\begin{array}{c}\text { Pearson } \\
\text { Correlation }\end{array}$ & $.662^{* *}$ & 1 \\
\hline & Sig. (2-tailed) & .000 & \\
\hline & $\mathrm{N}$ & 100 & 100 \\
\hline
\end{tabular}

Comparison of heights of government and private school students with respect to their different age groups: In private school sample of 100 students shows height $144.2219 \pm 2.5378 \mathrm{~cm}$ in age group 9-11 years and $157.0018 \pm 3.1670 \mathrm{~cm}$ is the height among age group 12-14 years. Similarly, out of 100 students from government school shows the average height of age group 9-11 years is $143.9176 \pm 1.1988 \mathrm{~cm}$ and that of age group 12-14 years is $153.7169 \pm 4.1713 \mathrm{~cm}$. (Table 2) 
Table 2: Height $(\mathrm{cm})$ comparison among students of government \& private schools with respect to their age groups $(n=100)$

\begin{tabular}{|c|c|c|}
\hline $\begin{array}{c}\text { Age group } \\
\text { (Years) }\end{array}$ & $\begin{array}{c}\text { Private School } \\
\text { (Height in cm) }\end{array}$ & $\begin{array}{c}\text { Government School } \\
\text { (Height in cm) }\end{array}$ \\
\hline $\mathbf{9 - 1 1}$ & $144.2219 \pm 2.5378$ & $143.9176 \pm 1.1988$ \\
\hline $\mathbf{1 2 - 1 4}$ & $157.0018 \pm 3.1670$ & $153.7169 \pm 4.1713$ \\
\hline
\end{tabular}

For government school children Mean Height (in cm) was $146.8100 \pm 4.34310$ \& for private school children 147.7600 \pm 5.04949 .

Correlation of height, between government and Private school children $\mathrm{n}=100$

\begin{tabular}{|c|c|c|c|}
\hline \multicolumn{2}{|c|}{ Correlations } & $\begin{array}{c}\text { Height } \\
\text { (Government) }\end{array}$ & $\begin{array}{l}\text { Height } \\
\text { (Private) }\end{array}$ \\
\hline \multirow{3}{*}{$\begin{array}{c}\text { Height } \\
\text { (Government) }\end{array}$} & Pearson Correlation & 1 & $.812^{* *}$ \\
\hline & Sig. (2-tailed) & & .000 \\
\hline & $\mathrm{N}$ & 100 & 100 \\
\hline \multirow{3}{*}{$\begin{array}{c}\text { Height } \\
\text { (Private) }\end{array}$} & $\begin{array}{c}\text { Pearson } \\
\text { Correlation }\end{array}$ & $.812^{* *}$ & 1 \\
\hline & Sig. (2-tailed) & .000 & \\
\hline & $\mathrm{N}$ & 100 & 100 \\
\hline
\end{tabular}

Z-Score was calculated by using following formula:

$Z$-Score $=X-\mu / \sigma$, where is $X=$ Raw Score, $\mu=$ Sample Mean, $\sigma=S D$. A value within $\pm 2 S D$ in these charts was considered as normal

\begin{tabular}{|c|c|c|c|c|c|}
\hline $\begin{array}{c}\text { Z-Score (Weight) } \\
\text { (Government) }\end{array}$ & Frequency & Percent & $\begin{array}{c}\text { Valid } \\
\text { Percent }\end{array}$ & $\begin{array}{c}\text { Cumulative } \\
\text { Percent }\end{array}$ \\
\hline \multirow{4}{*}{ Valid } & -1.21687 & 28 & 28.0 & 28.0 & 28.0 \\
\cline { 2 - 6 } & -.52152 & 17 & 17.0 & 17.0 & 45.0 \\
\cline { 2 - 6 } & .17384 & 24 & 24.0 & 24.0 & 69.0 \\
\cline { 2 - 6 } & .86919 & 14 & 14.0 & 14.0 & 83.0 \\
\cline { 2 - 6 } & 1.56455 & 17 & 17.0 & 17.0 & 100.0 \\
\cline { 2 - 6 } & Total & 100 & 100.0 & 100.0 & \\
\hline
\end{tabular}

Graph 3: For private school children

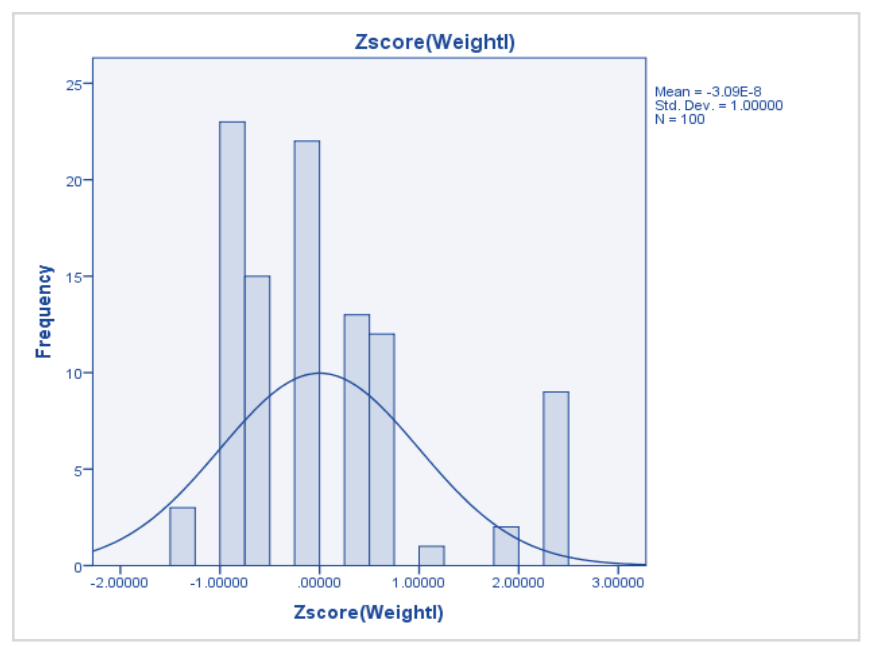

\section{DISCUSSION}

Nutrition of a primary school going child determines his life time health and his body strength, as this part of life is a dynamic stage of his physical and mental development. Regarding BMI, Montazerifar F et al, ${ }^{14}$ reported significantly lowered BMI $\left(15.6 \pm 2.1 \mathrm{~kg} / \mathrm{m}^{2}\right)$ in government school children as compared to private sector $\left(17.8 \pm 3.1 \mathrm{~kg} / \mathrm{m}^{2}\right)$. We also found similar results in our study with the mean BMI for private (18.0199 \pm 1.18686) and government (17.1091 \pm 1.67246) school children respectively.

In 2017, a report was forwarded by Alexia J De Piero et $a l, 15$ in which they found that in school children from Mountainous Areas of Argentinean Northwest, the main nutritional problems were the presence of overweight/obesity and stunting. Moreover, the same results were reported in previous studies conducted in the heights of northwestern Argentina and other countries with same ethnic, social, and geographic factors. ${ }^{16}$ In a study carried out by Sethy G et al, $69 \%$ of 300 children were belonged to under nutrition status with underweight $(55.3 \%)$, wasting $(75 \%)$ and stunting $(42 \%)$ respectively. ${ }^{17}$ Jerzy et al reported $19.2 \%$ overweight and $7.4 \%$ obese subjects. ${ }^{18}$ In our study, we found underweight children $64 \% \& 60 \%$ of government and private respectively mainly while overweight children were $4 \%$ in government sector and no case was reported in private sector. The difference of the results may be due to change of geographic characteristics as well as other socio-economical factors. Our study shows that socioeconomic factors are important since obesity and overweight increase with socio-economic status (SES). Higher SES groups should be targeted for overweight while underweight is a problem of lower SES. Meat intake and lack of physical activity are some of the other factors that have been highlighted in our study.

Cuevas García et al ${ }^{19}$ found a positive correlation between globalization processes such as internet access and increased TV ownership and over nutrition. Malnutrition is highly affected by economical factors. For example, in past, the decades leading up to the First World War, the most agricultural output was for export with high ratio of exports to subsistence food in total agricultural output. Many Jamaicans attributed low status for farming and hence food 'to eat' but high status to imported food. During Covid-19 pandemic, on one hand we had to face reduce tourism earnings affecting the economy of the country and on other hand the crisis also derived up food prices as a result of increased demand for food and changes in the supply chain, etc.

Globally, since the early 2000, for better and early management of malnutrition, community health workers diagnose the effected children with uncomplicated severe acute malnutrition and refer them to especially built health centers running specific outpatient therapeutic feeding programmes. ${ }^{20}$ In Pakistan Salma Shaik ${ }^{21}$ reported that, nutritional deficiency is responsible for school absence in 30\% school going children. According to research results of Fatima Shahryar, ${ }^{22}$ under five years 
of age, 38 percent of the children are stunted in Pakistan.

Moreover, alarming situation can be seen in Sindh, where she found approximately 50 percent of the children affected with increasing number in future.

\section{CONCLUSION}

According to our findings, malnutrition / under nutrition was more frequent in children of Government School, which implies that low socio-economic status directly affects the nutritional status.

\section{LIMITATIONS}

The study was limited to cases of Faisalabad Division. Nationwide sample collection can change the outcome.

\section{SUGGESTIONS / RECOMMENDATIONS}

UNICEF implemented a stunting reduction programmed in association with the Government of Pakistan and the United States Agency for International Development (USAID), to ensure a healthy life for all children. So, we can hope a better future for our school going children in coming years.

\section{CONFLICT OF INTEREST / DISCLOSURE}

No conflict of interest to be declared.

\section{ACKNOWLEDGEMENTS}

We are highly thankful to Assistant Prof. Dr. Mobeen, HOD, Forensic Medicine Department and Assistant Prof. Dr. Khalid, Community Medicine Department, Faisalabad Medical University, Faisalabad, Pakistan for their cooperation and guideline to conduct this research project.

\section{REFERENCES}

1. Karim A, Qaisar R. Anthropometric measurements of schoolgoinggirls of the Punjab, Pakistan. BMC Pediatrics. 2020;20:223.

2. Sabo RT, Lu Z, Daniels S, Sun SS. Serial childhood BMI and associations with adult hypertension and obesity: the Fels longitudinal study. Obesity. 2012;20(8):1741-3

3. Simko MD, Cowell C, Gilbride JA. Nutrition assessment: a comprehensive guide for planning intervention. 2nd ed. Gaithersburg, MD: Aspen Publishers; 1995.

4. De Onis M. Reliability of anthropometric measurements in the WHO Multicentre Growth Reference Study. Acta Paediatr. 2006; 450:38-46

5. Botero-Meneses JS, Aguilera-Otalvaro PA, Pradilla I, TaleroGutiérrez C, Ruiz-Sternberg ÁM, Vélez-van-Meerbeke A, PinzónRondón AM. Assessment of nutrition and learning skills in children aged 5-11 years old from two elementary schools in Chocó, Colombia. Heliyon. 2020;6(4):e03821.
6. E Niechwiej-Szwedo, Meier K, Christian L, Nouredanesh M, Tung J, Bryden P, et al, Concurrent maturation of visuomotor skills and motion perception in typically developing children and adolescents. Dev Psychobiol. 2020;62(3):353-67.

7. UNESCO: Education 2030 Framework for Action: Towards inclusive and equitable quality education and lifelong learning for all. In. Edited by UNESCO; 18, 2015.

8. Lane Js: A Life Free from Hunger. In. UK, London Save the Children; 2012

9. Haddad L, Hawkes C, Webb P, Thomas S, Beddington J, Waage J, Flynn D. A new global research agenda for food. Nature. 2016;540(7631):30-32.

10. Kamath SM, Venkatappa KG, Sparshadeep EM. Impact of Nutritional Status on Cognition in Institutionalized Orphans: A Pilot Study. J Clin Diagn Res. 2017;11(3):1-4.

11. Faught EL, Williams PL, Willows ND, Asbridge M, Veugelers PJ. The association between food insecurity and academic achievement in Canadian school-aged children. Public Health Nutr. 2017;20(15):2778-85.

12. Arimond M, Ruel MT. Dietary diversity is associated with child nutritional status: evidence from 11 demographic and health surveys. J Nutr. 2004;134(10):2579-85.

13. Okafor AM, Odo EO and Onodigbo EO. Dietary Diversity: Association with Academic Performance and Anthropometric Indices of Rural Nigerian School Children. Pak J Nutrit. 2020;19(2):61-7.

14. Montazerifar F, et al. Anthropometric Indices in Primary School Children of Iranshahr City, Iran. JNFS. 2019;4(4):249-55.

15. Alexia J De Piero, María C Rossi, María N et al; Food and Nutritional Assessment in School children from Mountainous Areas of Argentinean Northwest. J Clin Nutri \& Dietetics. 2017;3(4):24-32.

16. Medina O, Vargas S, Ibañez E, Rodriguez G. Anthropometric nutritional status of children and adolescents from 17 schools in the rural area of La Mesa municipality, Cundinamarca, Colombia. Salud Bosque Magazine, 2015;4:19-28.

17. Sethy G, Jena D, Jena P, Pradhan S, Biswas T. Prevalence of malnutrition among under five children of urban slums of Ber $\neg$ hampur, Odisha, India: a community a community based cross-sectional study. Int J Contemp Pediatrics. 2017;4(6):2180-6.

18. Słowik J, Grochowska-Niedworok E, Maciejewska-Paszek I, Kardas M, Niewiadomska E, Szostak-Trybuś M, Palka-Słowik M, Irzyniec T. Nutritional Status Assessment in Children and Adolescents with Various Levels of Physical Activity in Aspect of Obesity. Obes Facts. 2019;12(5):554-63.

19. Cuevas García-Dorado S, Cornselsen L, Smith R, Walls H. Economic globalization, nutrition and health: a review of quantitative evidence. Global Health. 2019;15(1):15.

20. Henrice Altink; Tackling child malnutrition in Jamaica, 1962-2020. Human Social Sci Commun. 2020;7:50-64.

21. Shaikh S, Chohan MN, Ahmed I, Memon H, Shaikh S. Assessment of The Nutritional Status by Measuring Body Mass Index and Screening of School Going Children of Khairpur Mirus Sindh. Professional Med J. 2020;27(4):725-9.

22. Fatima Shahryar; Saving children from stunting, UNICEF Pakistan for every child, April 2019 https://www.unicef.org/pakistan/stories/saving-childrenstunting 